This report was prepared as an accoun of wcrik sponsored by an agency of the United States Government. Neither the United States Goverament nor any asency thereof, nor any of their employees, makes any warranty, cxpress or implied, or assumes any legal liability or responsibility for the accuracy, completeness, or uscfulness of any information, apparatus, product, or process disclosed, or represents that its use would not infringe privately owned rights. Reference herein to any specilic commercial product, process, or service by trade name, Irademark, manufactuter, of otherwise does not necessarily constitute of imply its endorsemenl, recommendation, or favoting by the United States Government or any agency thereof. The views and opinions of authors expressed herein do not necessarily state or renlect those of the United Stales Government or any agency thereof.

\title{
Computer-Aided Methods of Determining Thyristor Thermal Transients
}

\author{
E. Lu and G. Bronner \\ Princeton Plasma Physics Laboratory \\ Princeton, New Jersey 08543
}

PPPL- -2548

DE88 015826

\begin{abstract}
An accurate tracing of the thyristor thermal reoponse is mvestigated. This paper offers several alternatives for thermal modeling and analvsis by using an electrical cireuit analog: topological method, cunvolution integral method, etc. These methods are adaptable to numerical solutions and well suited to the use of the digital computer.

The thermal analysis $\mathrm{c}$ thyristors was performed for the 1000 MVA converter system at the Princeten Plasma Physics Laboratory. Transient thermal impedance curves for individual thyristors in a given cooling arrangement were known from measurements and from manufacturer's data. The analysis pertains to almost any loading case, and the results are obtained in a numerical or a graphical format.
\end{abstract}




\section{Introduction}

In all electrical equipment temperature rise has an important effert on equipment rating. A thyristor is no exception. Any property of a thvristor is temperature-dependent. and the maximum allowable junction temperature is one factor that determines its rating. In order to provide the junction with sufficient themal reserve (the tempera. ture rise margin), it is necessary to assess correctly the temperature and transient temperat!re changes for normal and anomalous loading siruations.

Thermal conditions for a thyristor are typically calculated from power dissjpation, taking into consideration the possible load cycle, the current waveforms, and the cooling conditions. The total power losses, $P_{t o t}$, of a thyristor are the stum of the on-state losses, switching losses (losses during turning on and turning of the device), gate powet losses. off-state losses, and reverse losses [1]. At industrial frequencjes between 0 and 400 c.p.5., the on-state dissipation dominates the heating of the junction [2]. The other losses, within the margin of error, can be neglected. For any current waveform, the instantaneous on-state dissipation equals the product of peat on-state cursent and voltages. In Fig. 1 an on-state characteristic of a thyristor is shown. The instantaneous on-state voltage under consideration can be expressed as $v=r_{F} i+l_{T o}[1]$. Thus,

$$
\begin{aligned}
p & =v i \\
& =v_{T 0} i+r_{F} i^{2},
\end{aligned}
$$

where

$$
\begin{aligned}
& V_{T 0}=\text { threshold voltage } \\
& r_{F}=\text { forward resistance. }
\end{aligned}
$$

A portion of the heat is conducted through the casing and heat sink. The amount of heat conducted depends on the thermat resistance. The rest of the heat increases the device temperature. Thus, the junction temperature is a function of the dissipation as well as of the thermal resistances and capacitances.

In steady-state operation, after thermal equilibrium has set in, the heat flow rate and the temperature distribution in the system are constant. The released heat passes through a number of components 
made of different materials and geometries. Thermally, these parts can be modeled using their thermal resistances connected in series [3]. Figure 2 shows the thermal equivalent circuit of a steady-state, whese the heat is assumed to be dissipated at one point of the junction. $\theta, P$, and $R$ indicate temperature, power dissipation, and thermal resistance. respectivel $v$, and the subscripts $j, c, s$, and $a$ denote junction, casing. heat sink and ambient, respectively. The junction temperature rise abrive ambient temperisture is

$$
\theta_{J}=P\left(R_{j c}+R_{c\lrcorner}+R_{d a}\right) .
$$

In normal operation a thyristor is supplied from a conventional $60 \mathrm{~Hz}$ power system, so the conduction period, $T$, is a fraction of $1 / 60=0.0167$ seconds. In a three-phase ( 6 pulse) bridge circuit, the pulse lasts one-third of a cycle ( 120 electrical degrees). The conduction period is $0.0167 \times 120 / 360=5.6 \times 10^{-3}$ seconds as shown in part $B$ of Fig. $3^{\mathbf{l}}$. The timie dependence of the power loss is similar to that of the current. Hence, during the load cycle the device experiences several heating and cooling periods.

The similarity between the heat flow and Ohm's Law is conducive to the idea of finding analogies between heat transfer and the conduction of electricity. The concept of thermal resistance anticipates the concept of a thermal circuit as an analog to the electric circuit. A transient thermal impedance $Z_{\text {th }}(t)$, which approaches the thermal resistance $R_{t h}$ at $t \longrightarrow \infty$, can be employed to determine the maximum junction temperature in the pulsed operation. $Z_{\text {tht }}$ is defined as the change in temperature between two specified points or regions in response to the step function change in power dissipation 4.4 . The value is affected by the thermal capacitances as well as by the ther$\mathrm{mal}$ resistances of the device. If the time dependence of the transient thermal impedance of a thyristor (mounted on a given heat sink in a given cooling arrangement) is known, then the junction temperature $\theta_{j}$ is given at any arbitrary instant.

The analytic treatments of transient heat conditions for a thyristor are generally rather formidable. Satisfactory approximate solutions, however, can be obtained using mumerical methods suitable for digital

\footnotetext{
${ }^{1}$ This approximation assumes zero-lime for commutation.
} 
computers. In this paper, we present solutions which are based on an electrical anajog with a network synthesis and analysis lechnique. In the analog model, power dissipation correspinds to clirrent and temperature to voltage.

\section{Network Synthesis}

Synthesis is defined as the realization of passive networks that satisfy the given transfer functions. A solution may not exist if the given function is not realizable. A check should be made to determine whether the given function satisfies the necessary and sufficient conditions for physical realization.

In our synthesis application, the thermal impedance specification is given in a graphical form, i.e., transient thermal impedance curves for individual thyristors in a given cooling arrangement. In this case, before a network realization can be initiated, the given curve must be approximated by an appropriate rational function ming a restain curve fittang method. After the rational function has been deternined. there is no further approximation: realization of the rational function bi a network is exact.

\subsection{Approximation - Curve Fitting}

In curve fitting we are given n points

$$
\left(x_{1}, y_{1}\right), \ldots,\left(x_{n}, y_{n}\right)
$$

and we want to determine a function $f(x)$ such that

$$
f\left(x_{j}\right) \approx y_{j}, \quad j=1, \ldots, n .
$$

Figure 4 shows a typical transient thermal impedance curve (junctionto-water) with exponential characteristics that allow a series of decay exponential functions to be found. Our approach to curve fitting is to use successive regression in semilogarithmic space. A step-by-step pri,cedure is as follows: 
1. Sample a set of data points $t_{2} . Z_{t h t}\left(t_{2}\right)$ from the given transient thermal impedance curve.

2. Io start with. chouse a sel of new data prints $t_{2}, y\left(t_{i}\right)$, where $y\left(t_{z}\right)=R_{t h}-Z_{t h t}\left(t_{t}\right)$ and $R_{t h}$ is the steadv-state thermal impedance.

3. Graph the selected points on semilogarithmic scales and fit them with piecewise straight lines, satisfying $\max \frac{g\left(t_{1}\right)-y\left(t_{3}\right)}{g\left(t_{1}\right)}<\epsilon$. where $i t_{i}, g\left(t_{i}\right) !$ is the point lying on the line.

4. Define a difference function for the $j_{t h}$-time segment,

$$
\delta_{j}(t)=g(t)-f_{j-1}(t) \quad(j=1, n-1),
$$

where $f_{j-1}(t)$ is the analytic term for the $(j+1)_{h \text {-time segment }}$ corresponding to the $(j-1)_{\mathrm{th}}$-straight line and $n$ is the total number of straight lines.

5. Initiate the fitting calculation from the right side to the left side in the coordinate :

- The equation for the $n_{t h}$-time segment,

$$
\ln \int_{n}(t)=-\alpha_{n} t+\ln C_{n} \ldots
$$

By taking an antilogarithm on both sides,

$$
f_{n}(t)=C_{n} e^{-a_{n} t},
$$

where

$$
\left\{\begin{array}{l}
a_{n}=\ln \frac{g\left(t_{n, 1}\right)}{g\left(t_{n, 2}\right)} /\left(t_{n, 2}-t_{n, 1}\right) \\
c_{n}=g\left(t_{n, 1}\right) e^{a_{n} t_{n, 1}} .
\end{array}\right.
$$

The subscripts 1 and 2 denote two distinctive points on the $n_{e h}$-straight line. The same is true for the following.

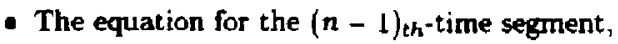

$$
\ln \delta_{n-1}(t)=-\alpha_{n-1} t+\ln C_{n-1} .
$$

By taking an antilogarithm on both sides,

$$
\delta_{n-1}(t)=C_{n-1} e^{-a_{n-1} t}
$$


where

$$
\left\{\begin{array}{l}
a_{n 1}=\ln \frac{\delta_{n-1}\left(t_{n-1.1}\right)}{\delta_{n-1}\left(t_{n-1.2}\right)},\left(t_{n}: 2-t_{n-1.1}\right) \\
C_{n-1}=\delta_{n-1}\left(t_{n-1.1}\right) e^{\alpha_{n-1} t_{n-1.1}} .
\end{array}\right.
$$

Guided by Eq. (1), we determine:

$$
\begin{aligned}
f_{n-1}(t) & =f_{n}(t)+\delta_{n-1}(t) \\
& =C_{n} e^{a_{n} t}-C_{n-1} e^{-a_{n-1} t}
\end{aligned}
$$

- In general, we have

$$
\begin{aligned}
\delta_{n-i}(t) & =g(t)-f_{n-i+1}(t) \\
& =C_{n-i} e^{-\alpha_{n-1} t} \quad(i=1, n-1)
\end{aligned}
$$

where

$$
\left\{\begin{array}{l}
a_{n-i}=\ln \frac{\delta n-i\left(t_{n-1,1}\right)}{\delta_{n-i}\left(t_{n-1,2}\right)} /\left(t_{n-i, 2}-t_{n-i, 1}\right) \\
C_{n-i}=\delta_{n-i}\left(t_{n-i, 1}\right) e^{\alpha_{n-i} t_{n-t, 1}}
\end{array}\right.
$$

Thus,

$$
\begin{aligned}
f_{n-i}(t) & =f_{n-i+1}(t)+\delta_{n-i}(t) \\
& =C_{n} e^{-\alpha_{n} t}+\cdots+C_{n-i} e^{-\alpha_{n-1} t} \quad(i=1, n-1)
\end{aligned}
$$

in terms of the definition, $\delta_{n-i}(t)$ nearly drops down to the zero when approaching the end of the $(n-i)_{t h}$-time interval, and $f_{n-i}(t) \approx g(i)$ thenceforth.

6. Following (n-1)-steps operations we can represent $Z_{t h t}(t)$, referring to (2):

$$
\begin{aligned}
Z_{t h t}(t) & =R_{t h}-f_{1}(t) \\
& =R_{t h}-C_{n} e^{-\alpha_{n} t}-\cdots-C_{1} e^{-\alpha_{1} t} \\
& =R_{t h}-\sum_{i=1}^{n} C_{1} e^{-\alpha_{1} t}
\end{aligned}
$$


The above procedure can be easily implemented in a computer program. A How chart used to determine the curve fitting coefficients $\left(i, \alpha_{1}(1=1 . n)\right.$ is shown in the Appendix. Based on the series fitting that is given in Fig. 5. a close agreement with the original thermal impedance curve is clearlv evident. where $n=5$ was chosen.

\subsection{Network Realization}

To transform the transient thermal impedance $Z_{\text {tht }}(t)$ from a time domain (Eq.2) to an analog circuit takes two steps:

- Find the system function of Eq.(2) with respect to a unit-step excitation.

- Convert the system function into an RC network, which is suggested by the nature of the thermal problem.

A driving-point function $G$ of the system shown in Fig. 6 , may be derived from the definition of the transjent thermal impedance and Eq. (2):

$$
\begin{aligned}
G(s) & =\frac{C\left[Z_{\text {tht }}(t)\right]}{C[p(t)]} \\
& =\frac{Z_{t h t}(s)}{P(s)} \\
& =\left(\frac{R_{t h}}{s}-\sum_{i=1}^{n} \frac{C_{i}}{s+\alpha_{i}}\right) / \frac{1}{s} \\
& =\left(R_{t h}-\sum_{i=1}^{n} C_{i}\right)+\sum_{i=1}^{n} \frac{C_{i} a_{i}}{s+\alpha_{i}} \\
& =k_{0}+\sum_{i=1}^{n} \frac{k_{i}}{s+a_{i}},
\end{aligned}
$$

where $k_{0}=R_{t h}-\sum_{i=1}^{n} C_{i}, k_{i}=C_{i} \alpha_{i}$. The function $G(s)$ satisfies the necessary and sufficient conditions for physical realization [5].

Through a sequence of mathematical operations with multiplication and addition of polynomials, the system function $G$ shown in Eq.(3) can be transcribed to a rational-fraction of two polynomials 
with real coefficients.

$$
G(s)=\frac{a_{n} s^{n}-a_{n-1} s^{n-1}-\cdots-a_{n}}{b_{n} s^{n}-b_{n-1} s^{n-1}-\cdots-b_{0}} .
$$

The laborious computing process may be implemented by digital computer. The basic problem is to develop a polynomial-multiplication algorithm by means of a multiplication of matrices. while the addition algorithm is straightforward and omitted herein. Let $P(s)$ be a polynomial oi degree $m$ which has the form

$$
P(s)=p_{m} s^{m}+p_{m-1} s^{m-1}+\cdots+p_{1} s+p_{0} .
$$

Let $Q(s)$ be a polynomial of degree $n$ which has the form

$$
Q(s)=q_{n} s^{n}+q_{n-1} s^{n-1}+\cdots+q_{1} s+q_{0} .
$$

Define a $(m+1) \times 1$ rolumn vector $\overrightarrow{\mathbf{P}}$ with elements as shown in $(5)$. Note the superseript, $t$, denotes a transpose.

$$
\overrightarrow{\mathbf{P}} \stackrel{\text { def }}{=}\left(p_{m}, p_{m-1}, \ldots, p_{1}, p_{0}\right)^{\ell} .
$$

Then, construct an $(m+n+1) \times(n+1)$ matrix $\overrightarrow{\mathbf{C}}$ with $(n+1)$ column vectors $\overrightarrow{\mathbf{P}}$ where the $i_{\text {eh }}$-column vector starts with the $i_{t h}$-row and all other elements are zero, assuming $m \geq n$ :

$$
\overrightarrow{\mathbf{C}} \stackrel{\text { def }}{=} \underbrace{\{m-n+1\} \times(n+1)}_{\left\{\begin{array}{lllll}
p_{m} & & & & \\
p_{m-1} & p_{m} & & & \\
p_{m-2} & p_{m-1} & p_{m} & & \\
\vdots & \vdots & \vdots & \ddots & \\
p_{0} & p_{1} & p_{2} & \cdots & p_{n} \\
& p_{0} & p_{1} & \cdots & p_{n-1} \\
& & p_{0} & \cdots & p_{n-2} \\
& & & \ddots & \vdots \\
& & & & p_{0}
\end{array}\right]}
$$

Define a $(n+1) \times 1$ column multiplying vector $\overrightarrow{\mathbf{Q}}$ with elements as shown in (6).

$$
\overrightarrow{\mathbf{Q}} \stackrel{\text { deff }}{=}\left(q_{n}, q_{n-1}, \ldots, q_{1}, q_{\mathfrak{D}}\right)^{t}
$$


Thus, the product of matrices $\overrightarrow{\mathbf{C}} \times \overrightarrow{\mathbf{Q}}$ is a $(m+n-1) \times 1$ matrix which contains the coefficients of the product $F(s)=P(s) \times Q(s)$. A listing of subroutine PMUL which will perform such an operation is given in the Appendix.

The procedures for combining groups of two fractions in Eq.(3) were developed with matrix multiplication and addition arithmetic. Instead of a detailed description of the operation, several steps to find the coefficients of the numerator and denominator polynomials are demonstrated as follows:

$\frac{k_{1}}{s+\alpha_{1}}+\frac{k_{2}}{s+\alpha_{2}}=\frac{k_{1}\left(s+a_{2}\right)+k_{2}\left(s+a_{1}\right)}{\left(s+a_{1}\right)\left(s+\alpha_{2}\right)}=\frac{\left(k_{1}+k_{2}\right) s+\left(k_{1} a_{2}+k_{2} a_{1}\right)}{s^{2}+\left(a_{1}+a_{2}\right) s+\alpha_{1} a_{2}}$.

The above step in matrix arithmetic will read :

For the numerator,

$$
\left[\begin{array}{cc}
k_{1} & 0 \\
0 & k_{1}
\end{array}\right]\left[\begin{array}{c}
1 \\
\alpha_{2}
\end{array}\right]+\left[\begin{array}{cc}
k_{2} & 0 \\
0 & k_{2}
\end{array}\right]\left[\begin{array}{c}
1 \\
a_{1}
\end{array}\right]=\left[\begin{array}{c}
k_{1}+k_{2} \\
k_{1} \alpha_{2}+k_{2} a_{1}
\end{array}\right]
$$

i.e., the top row has the coefficient of $s^{1}$, the second row has $s^{0}$. In general, the $i_{t h}$-row contains the coefficient of $a^{\text {ndeg-it+1 }}$, where ndeg is the degree of the product polynomial.

For the denominator,

$$
\left[\begin{array}{cc}
1 & 0 \\
a_{1} & 1 \\
0 & a_{1}
\end{array}\right]\left[\begin{array}{c}
1 \\
a_{2}
\end{array}\right]=\left[\begin{array}{c}
1 \\
a_{1}+a_{2} \\
a_{1} \alpha_{2}
\end{array}\right]
$$

i.e., the top row has the coefficient of $s^{2}$, etc.

and continue with

$$
\frac{\left(k_{1}+k_{2}\right) s+\left(k_{1} a_{2}+k_{2} \alpha_{1}\right)}{s^{2}-\left(\alpha_{1}+a_{2}\right) s+\alpha_{1} a_{2}}+\frac{k_{3}}{s+\alpha_{3}}=\cdots
$$

for numerator,

$$
\begin{aligned}
{\left[\begin{array}{cc}
k_{1}-k_{2} & 0 \\
k_{1} \alpha_{2}-k_{2} \alpha_{1} & k_{1}+k_{2} \\
0 & k_{1} \alpha_{2} \cdot k_{2} \alpha_{1}
\end{array}\right]\left[\begin{array}{c}
1 \\
a_{3}
\end{array}\right]+} & {\left[\begin{array}{ccc}
k_{3} & 0 & 0 \\
0 & k_{3} & 0 \\
0 & 0 & k_{3}
\end{array}\right]\left[\begin{array}{c}
1 \\
\alpha_{1}+\alpha_{2} \\
\alpha_{1} \alpha_{2}
\end{array}\right] } \\
= & {\left[\begin{array}{c}
k_{1}-k_{2}-k_{3} \\
k_{1}\left(\alpha_{2}+\alpha_{3}\right)+k_{2}\left(\dot{\alpha}_{1}-\alpha_{3}\right)+k_{3}\left(\alpha_{1}-\alpha_{2}\right) \\
k_{1} \alpha_{2} \alpha_{3}-k_{2} \alpha_{1} \alpha_{1}+k_{3} \alpha_{1} \alpha_{2}
\end{array}\right] }
\end{aligned}
$$


for denominator,

$$
\left[\begin{array}{cc}
1 & 0 \\
a_{1}-\alpha_{2} & 1 \\
a_{1} \alpha_{2} & a_{1}-a_{2} \\
0 & \alpha_{1} \alpha_{2}
\end{array}\right]\left[\begin{array}{c}
1 \\
a_{3}
\end{array}\right]=\left[\begin{array}{c}
1 \\
\alpha_{1}-a_{2}-a_{3} \\
\alpha_{1} \alpha_{2}+\alpha_{1} a_{3}+a_{2} \alpha_{3} \\
\alpha_{1} a_{2} \alpha_{3}
\end{array}\right]
$$

The algorithm may be easily designed by calling the subroutine PMUL to collect the appropriate terms for powers of $s$.

The rational fraction as shown in Eq.(4), in turn, can be manipulated to define an $\mathrm{FC}$ ladder with resistances in the series arms and capacitances in the shunt arms alternately where the values of $\mathrm{A}$ and $\mathrm{C}$ are determined by the steps of a continued-fraction expansion 5 . The first step of such a process may be shown as follows, assuming $G(0)>G(\infty)$ and $b_{0} \neq 0[5]$ :

$$
\begin{gathered}
\frac{b_{n} s^{n}+b_{n-1} s^{n-1}+\cdots\left|a_{n} s^{n} \div a_{n-1} s^{n-1}+\cdots\right| \overbrace{a_{n} / b_{n}}^{z_{1}}}{\underbrace{\frac{a_{n}}{a_{n-1}-\frac{a_{n-1}}{b_{n}} b_{n-1}} s^{n-1}+\cdots}_{a_{n-1}^{\prime}} s^{n-1}+\cdots}
\end{gathered}
$$

Thus, from the first step, we obtain a result of the form,

$$
G(s)=\frac{A(s)}{B(s)}=\frac{a_{n}}{b_{n}}+\frac{1}{\frac{b_{n} e^{n}+b_{n-1} n^{n-1}+\cdots}{a_{n-1}^{n} a^{n-1}+a_{n-2}^{\prime} s^{n-2}+\cdots}},
$$

where $a_{n-1}^{\prime}=\left[a_{n-1}-\frac{a_{n}}{b_{n}} b_{n-1}\right]$, etc. The next step is

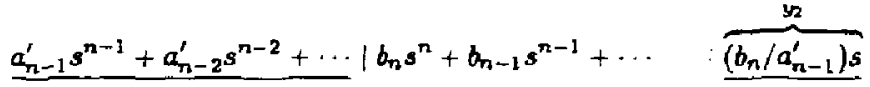

$$
\begin{aligned}
& \frac{b_{n}}{a_{n-1}^{\prime}} a_{n-2}^{\prime} s^{n-1}+\cdots \\
& \underbrace{\overline{\left.b_{n-1}-\frac{b_{n}}{a_{n-1}^{\prime}} a_{n-2}^{\prime}\right]} s^{n-1}+\cdots}_{b_{n-1}^{\prime}}
\end{aligned}
$$


Up to the second step. we may write the function in the form.

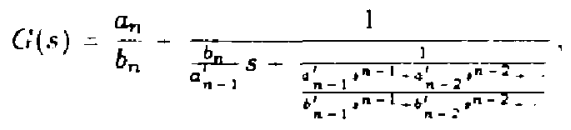

where $b_{n-1}^{\prime}=b_{n-1}-\frac{b_{n}}{a_{n-1}^{\prime}} a_{n-2 .}^{\prime}$, etc.

The repetition of the basic two-step procedure for cycles will con. tinue to give partial quotjents that ... $z$ alternately positive constants and linear terms with positive coefficients until the number of partial quotients obtained in the continued-fraction expansion is equal to one more than the number of internal critical frequencies, which are the zeros and poles collectively [5:. The algorithm is easily implemented by a subroutine CFE which is listed in the Appendix.

Figure 6 shows the schematic representation of the ladder network corresponding to this expansion on the basis of the transient thermal impedance curve shown in Fig. 4 with resistance terminations at both input and output. The series arms are labeled with their impedance values $z$ and the shunt arms with their admittance malues (capacitances) $y$. There is a value of thermal resistance assigned to each group of resistors in series. The first group identified is the internal thermal resistance from junction to case, given in the individual device specifications. Next is the sum of the contact thermal resistance from the case to the heat exchanger and the thermal resistance of the heat exchanger to the cooling medium, of which value is the difference between two steady-state thermal impedances as shown in Fig. 4 .

\section{Transient Thermal Analysis}

The previous model was developed to perform the thermal analysis. A solution always exists and is unique where an input is given. There are several methods to solve the thermal problem which are equivalent to solving the transient behavior of an electrical circuit. 


\subsection{Classical and State-Variable Methods}

A part of synthesis - network realization - bears directly on the classical and state-varzable methods and provides considerable insight into thermal equiralent circuit operation. which allows the temperature distribution in the thermal system to be found.

The dynamics of an RC circuit are determined by the rate of change of the capacitor voltages in the circuit. The first-order ordinary differential equations describing the circuit should be established in terms of the topology of the circuit, and solved by numeri, $x$ ineans due to discontinuous loading cases in converter bridges. Both classical and state-variable methods present such a scheme in obtaining the time-domain response of networks to arbitrary inputs. The detailed contents and computer algorithrns may be found in standard texts and are omitted here.

\subsection{Convolution Integral Method}

If we are interested only in the response on thyrietar. junctions, then numerical solution of the convolution integral method should be used. The advantage over the other methods is to omit the lengthy network realization process mentioned in the previous section and rely on the system function defined in Eq.(3). This will be elaborated below.

Assume a network's response to an impulse input $\delta(t)$ is known $h(t)$, then, for an arbitrary input $p(t)$, the convolution integral will find the response $\theta_{j}(\ell)[6]$ :

$$
\begin{aligned}
\theta_{j}(t) & =\int_{0}^{t} p(t-\tau) h(\tau) d \tau \\
& =\int_{0}^{t} p(\tau) h(t-\tau) d \tau \\
& =p(t) * h(t) \quad(t \geq 0) .
\end{aligned}
$$

The integral applies only to linear, time-invariant networks and requires only that $p(t)$ and $h(t)$ be Laplace transformable. The situation is illustrated in Fig.7. In the upper figure, we introduce an impulse to the zero-s'ate network $G$ at $t=0$ and obtain the output response 
$h(t)$. Now if we apply some other function $p(t)$ at $t=0$ to the same network $G$. we obtain the response $\theta_{j}(t)=p(t)=h(t)$. In Fig. 7 the network is a hlack box, and $G(s)$ is defined by input-output relations in accordance with Eq. (3). The inverse Laplace transform of the sys. tem function $G(s)$ shows that the impulse response includes terms of the form $k_{i} e^{-a_{1} t}$, where $k_{i}$ is a constant and $\alpha_{i}$ is the zero of the denominator polynomial. From Eq.(3),

$$
\begin{aligned}
h(t) & =\mathcal{L}^{-1}[G(s)\} \\
& =k_{0} \delta(t)-\sum_{i=1}^{n} k_{i} e^{-a_{1} t}
\end{aligned}
$$

Thus, to arbitary input $p(t)$ :

$$
\begin{aligned}
\theta_{j}(t) & =p(t) * h(t) \\
& =p(t) *\left[k_{0} \delta(t) \div \sum_{i=1}^{n} k_{i} e^{-\alpha_{i} t}\right] \\
& =k_{0} p(t) * \delta(t) \div \sum_{i=1}^{n} k_{i}\left[p(t) * e^{-\alpha_{1} t}\right] \\
& =k_{0} p(t)+\sum_{i=1}^{n} k_{i} \int_{0}^{t} p(\tau) e^{-\alpha_{1}(t-\tau) d \tau} \\
& =k_{0} p(t)+\sum_{i=1}^{n} k_{i} e^{-\alpha_{i} t} \underbrace{\int_{0}^{t} p(\tau) e^{\alpha_{i} \tau} d \tau}_{J_{1}(t)} \quad(t \geq 0) .
\end{aligned}
$$

We noted that the response of a dynamic network depends on present and past events. The partial solution, i.e. the value of integration $J_{i}(t)=\int_{0}^{t} p(\tau) e^{\alpha_{i} \tau} d \tau$, may be obtained analytically in a few simple cases, such as $p(t)=c$ or $p(t)=k t+c$. For varying loading requirements a numerical method of approximate integration should be used when analytical solutions are difficult to obtain. The results are accurate only within some tolerance, depending on the program and the basic machine characteristics.

For a certain loading cycle as shown in part $A$ of Fig. 3 and a current through an individual thvristor in part $B$, a trapezoidal integration algorithm may be adopted. The flowchart for the logic of such 
a numerical algorithm to find the thvristor thermal response is presented in the Appendix. The computer algorithm advances bv taking finite steps in the independent variable 1. During pulsed-operation a suitabjy small increment is clearly required for accuraiv. For the sake of economy. values of integration in which the algorithm is equipped to recognize jump discontinuities, once calculated, are saved as the memory of past events for the next step. The flowchart may help to explain the performance. The response obtained using the algorithm, corresponding to the loading case with reference to Fig. 3 , is sketched in Fig. 9.

\section{Conclusions}

Methods to analyze the transient thermal response of a thyristor were developed. An improved knowledge of the junction temperature excursion can result in better protection and significant savings for pulsed loads or transient loading conditions. An important preliminary finding indicates significant junction cooling in milliseconds of the off periods. The continuous current operation is considered as the special case of the discontinuous current operation to which this analysis is dedicated.

\section{Acknowledgments}

The authors would like to thank the Engineering Analysis Division for support during the course of this work, and also thank $\mathrm{L}$. Ku who helped in developing the curve fitting technique. The work was sponsored by the U. S. Dept. of Energy Contract No. DE-AC02-76CHO-3073. 


\section{References}

1' Thorborg, K., Power Electronics, 2nd Ed.. S. T. Teknik, Sweden, 1985, fp.2:1-2:18.

2) Csáki, F., Ganszky, K., Ipsits, I. and Marti, S., Pouer Electronics, Akadémiai Kiadó, Budapest, 1975, p.567.

'3) Sugandhi, R. K. and Sugandhi, K. K., Thyristors Theory and Applications, 2nd Ed., John Wiley \& Sons, Inc., New York, 1984, pp.25-35.

4] The Engineering Staff of International Rectifier, SCR Applications Handbook, Lnternational Rectifier Corp., El Segundo, 1974, p.47t.

i5] Weinberg, L., Network Analysis and Synthesis, McGraw-Hill Book Company,Inc., New York, 1962.

[6] Jensen, R. W. and Watkins, B. O., Network Analysis Theory and Computer Methods, Prentice-Hall, Inc., Englewood Cliffs, 1974, pp.307-313. 


\section{Appendix}

\section{A Flow Chart for Curve Fitting}

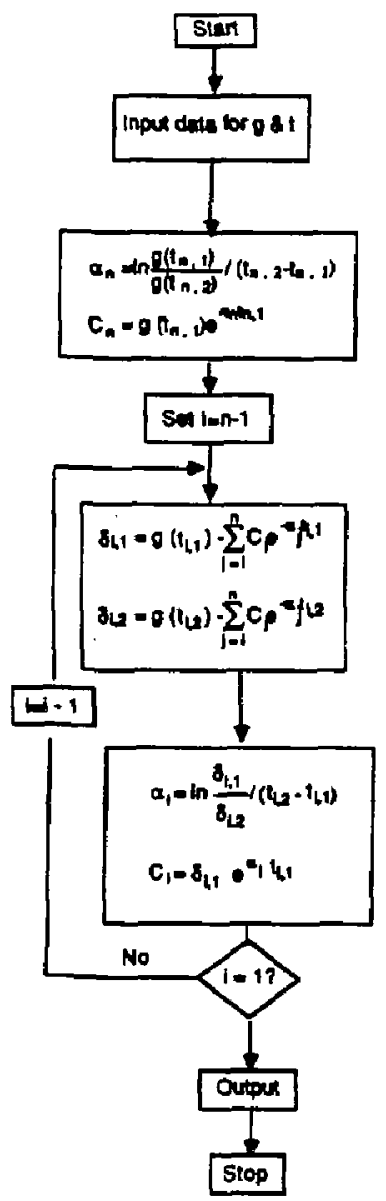


A Listing for the Subroutine PMUL

abroutine pul $(p, q, q, n, t, m)$

Subroutine for performing altiplicetion of polynomiale $f(a)$ ap(a) wa(s).

Araumente - - tore of polynowiel p(s). (input)

- - errey of length w1 centwining the coefpiciente of polynowiel p(a). (input)

$n$ - Lerce of polynemiel (e). (input)

a - errey of length n+l conteining the coefficiente of polynowiol $q(\theta)$. (input)

an an deares of product miynamial $P(a)$. (input)

$f$ - auteut erray of length mel centeining the

dimeneion $(0: n), q(0 ; n), f(B: n)$

Initiate the coefficients of the 1 errey to sere.

do 1 in, in

$f(i)=$.

1 continue

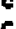

Compute the ceofticiente of torms with pepers 1 (ien,inn).

do $1=0$

do 2 i=t

$f(n-i)=i(-i+j) \bullet a(n-j)+1(m-i)$

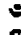

Tont to are cortel in thet aniet number of tore

to the shere aumetion ia $n+1$ if $n>n$.

if (1.0.n) op to 3

centinue

continue

Cenpute the coeptielente of taras ith perorr i (i=a,n-1).

do 5 i $=n-1,0,-1$

do $4 j=0$

(i) $=(j) \in q(i-j)+1$ (i)

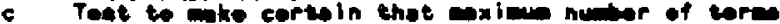

c to the abeve autotion it $0+2$ if $n<n$.

if $(1.0 .6)$ to

4 continue

continue

roturn

end 
A Ljsting for the Subroutine CFE

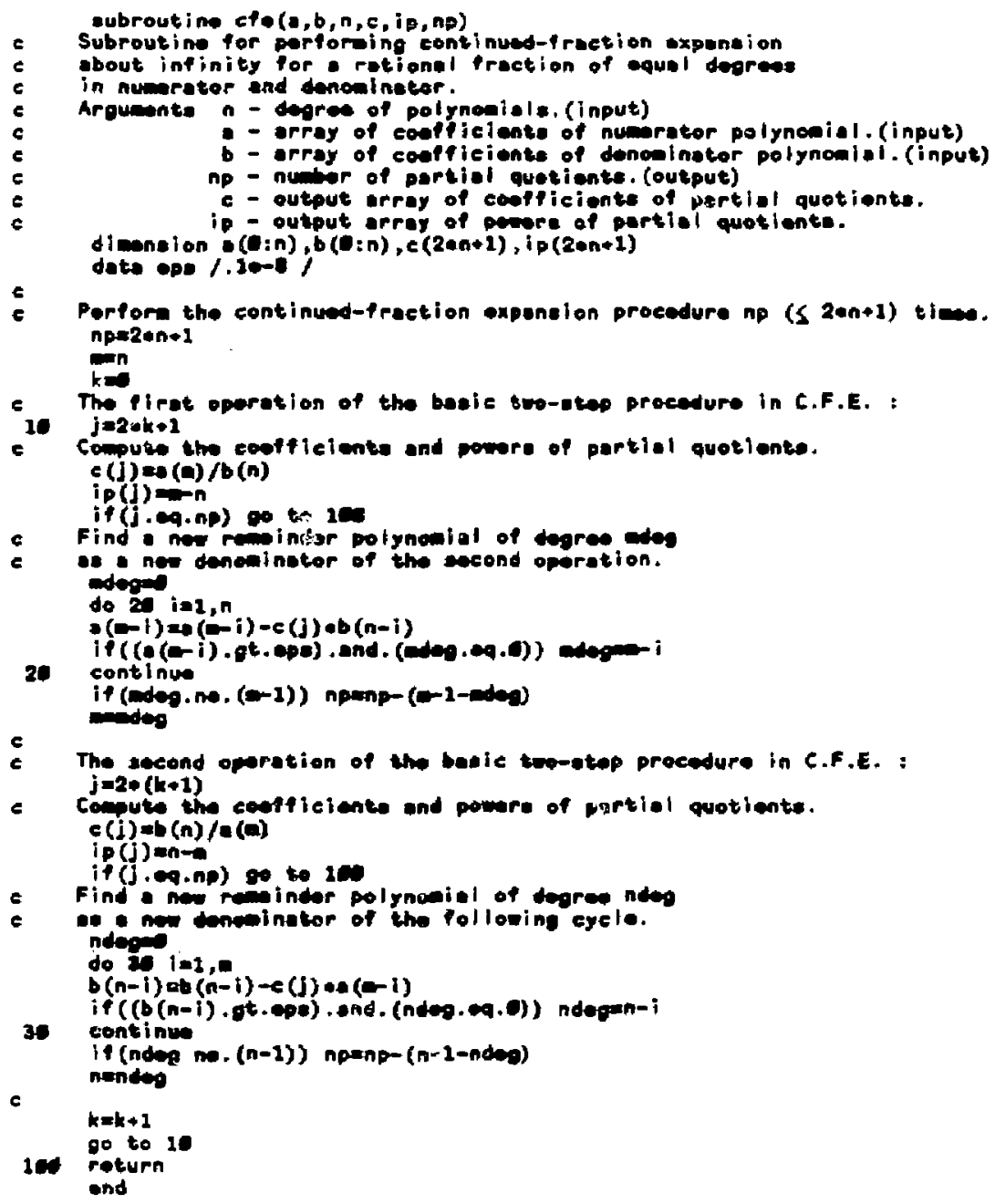


A Flow Chart for Finding Response by Trapezoidal Algorithm

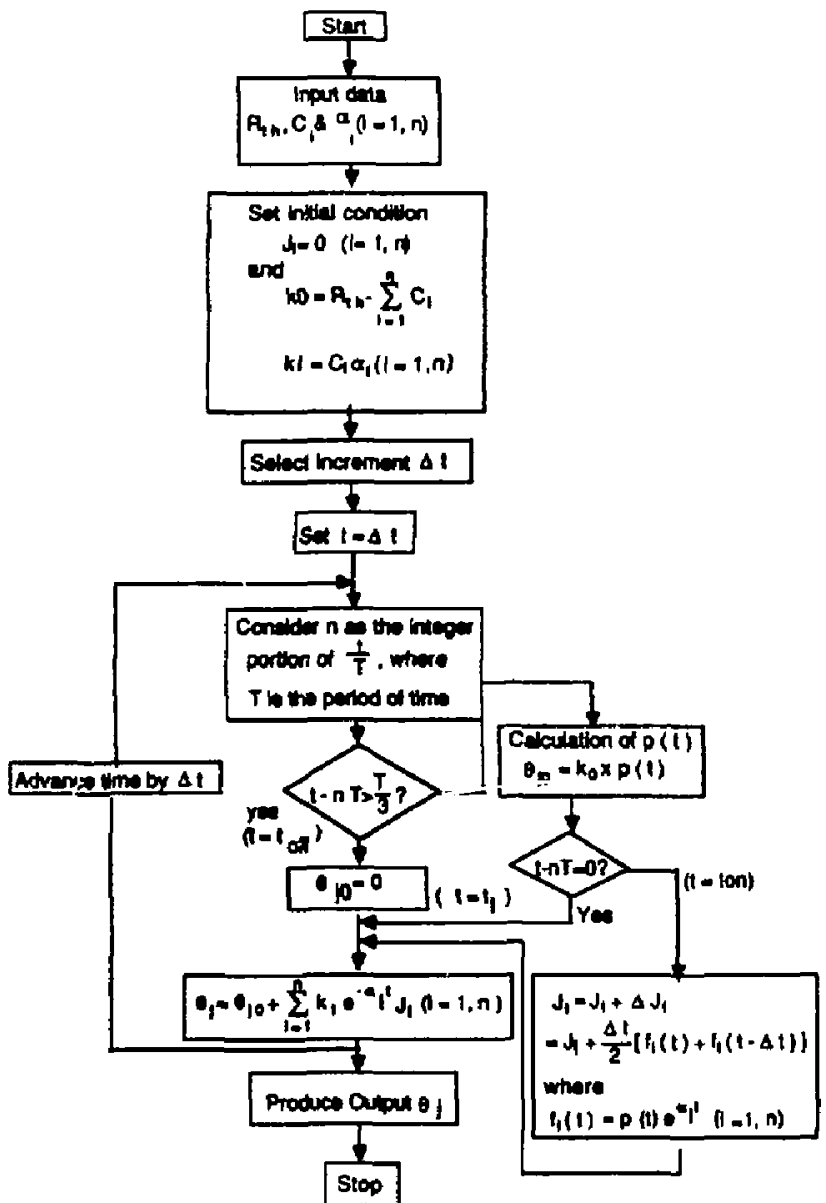

$\dagger$ with reference to $F$ ig. 8 


\section{Figure Captions}

Fig. I Firward drop curve for currents, shouing an on-state characlerist is of a thvristor

Fig. 2 Thermal model of a thyristor in steadv-state operations.

Fig. 3 TFTR loading curves. Part $B$ represents the current through individual thyristors in a three-phase $(6$ pulse) bridge circuit. supplied from a conventional $60 \mathrm{~Hz}$ power svstem.

Fig. 4 Transient thermal impedance curve for individual thyristors in a given cooling arrangement from measurements and manufacturer's data.

Fig. 5 Transient thermal impedance fitting curve bv approximation.

Fig. G Thermal model of the thytistor corresponding to Fig. 4. where

$$
\begin{aligned}
Z_{t h t}(t)= & R_{t h}-\sum_{i=1}^{5} C_{t} e^{-\alpha, t} \\
= & 0.07-0.04899 e^{-0.03892 t}-0.00982 \pi e^{-0.4274 t}- \\
& 0.003508 e^{-1.964 t}-0.00453 e^{-11.02 t}-0.002049 e^{-183.3 t} \\
& \left({ }^{\circ} \mathrm{C} / \mathrm{H}\right)
\end{aligned}
$$

and

$G(s)=\frac{11.001096 s^{5}+0.6541 s^{4}-19.60 s^{3}-67.66 s^{2}-47.46 s-4.620}{s^{5}+196.8 s^{4}+2493 . s^{3}-5089 . s^{2}+1881 . s-65.99}$

Fig. 7 Dlustration of Convolution.

Fig. 8 Geometrical interpretation of a definite integral having a pulsedintegrand with jump discontinuities. As shown in the figure. $t_{o n}$, $t_{o f f}$, and $t_{l}$ indicate time during on period. off period, and leading edge, respectively. $T$ is the period of time.

Fig. 9 Thyristor thermal response curves, carried out on the transient thermal impedance curve in Fig. 4 and the loading case with reference to Fig. 3. Part $B$ shows the enlargement of a small interval. It is obvious that the temperature rise and fall curves follow the well-known exponential law. where jump dis. continuities are caused by the assumption of zero-time commu. tation. 


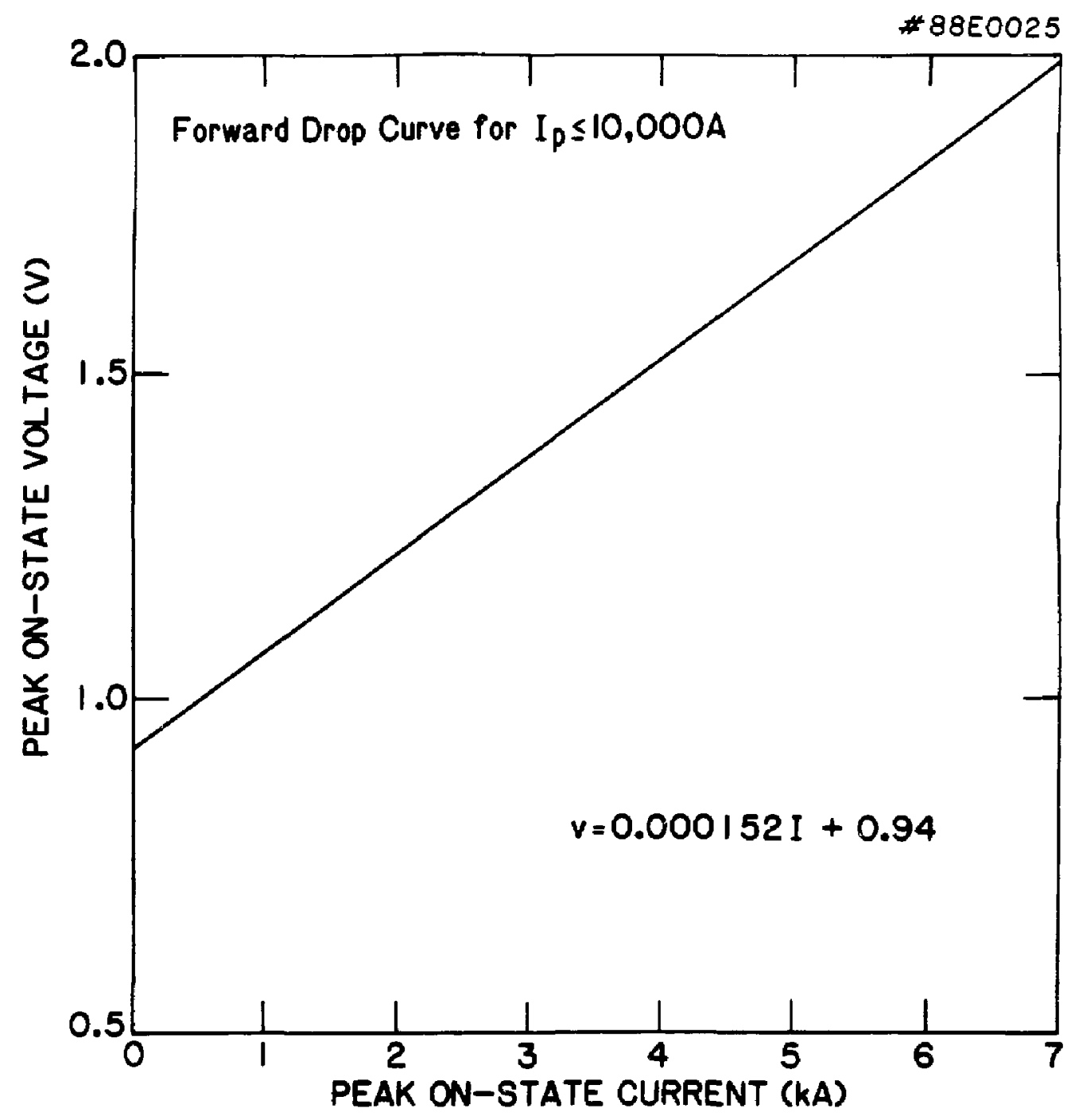

Fig. 1 
\# 88E0021

THERMAL MODEL OF A THYRISTOR IN STEADY-STATE OPERATION

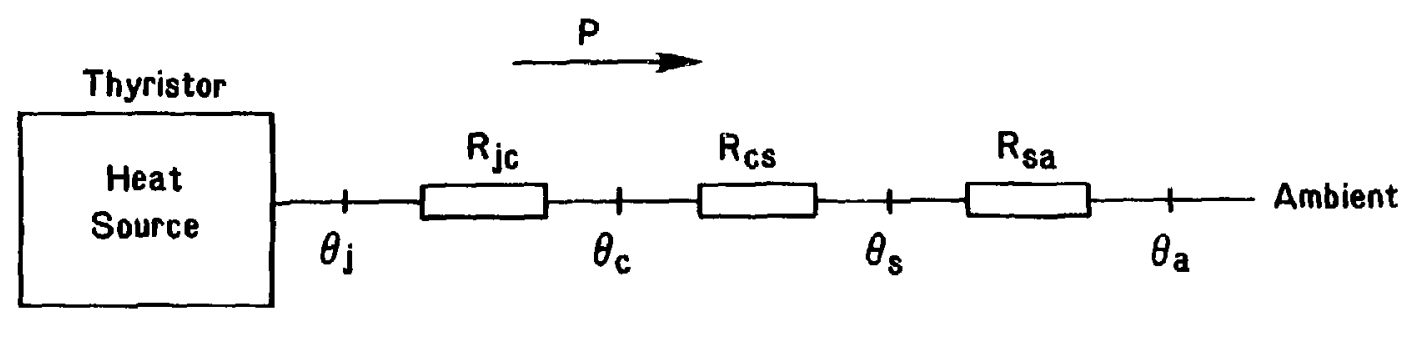

F1g. 2 

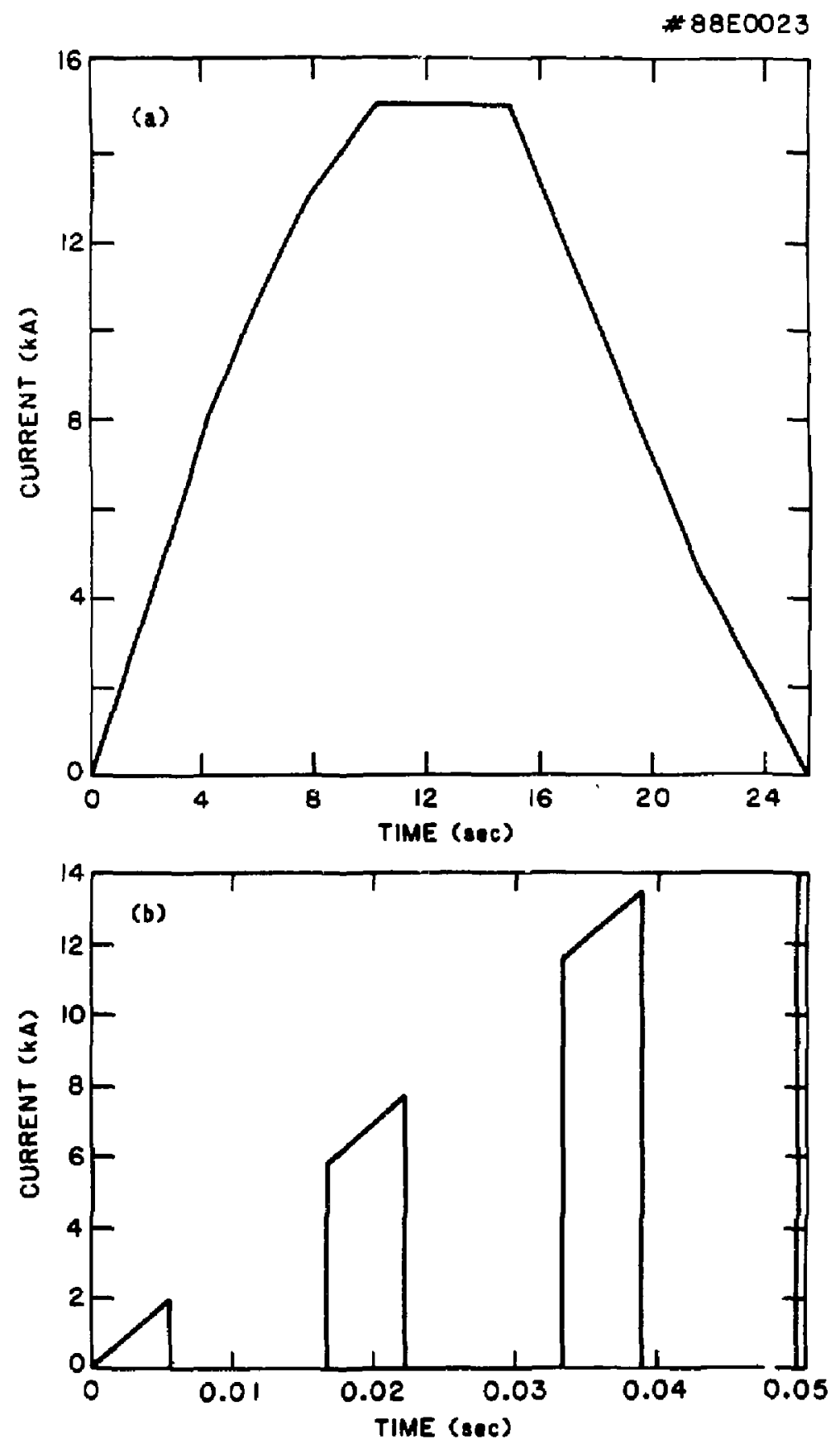

Fig. 3 
- $.67 \mathrm{FI}$

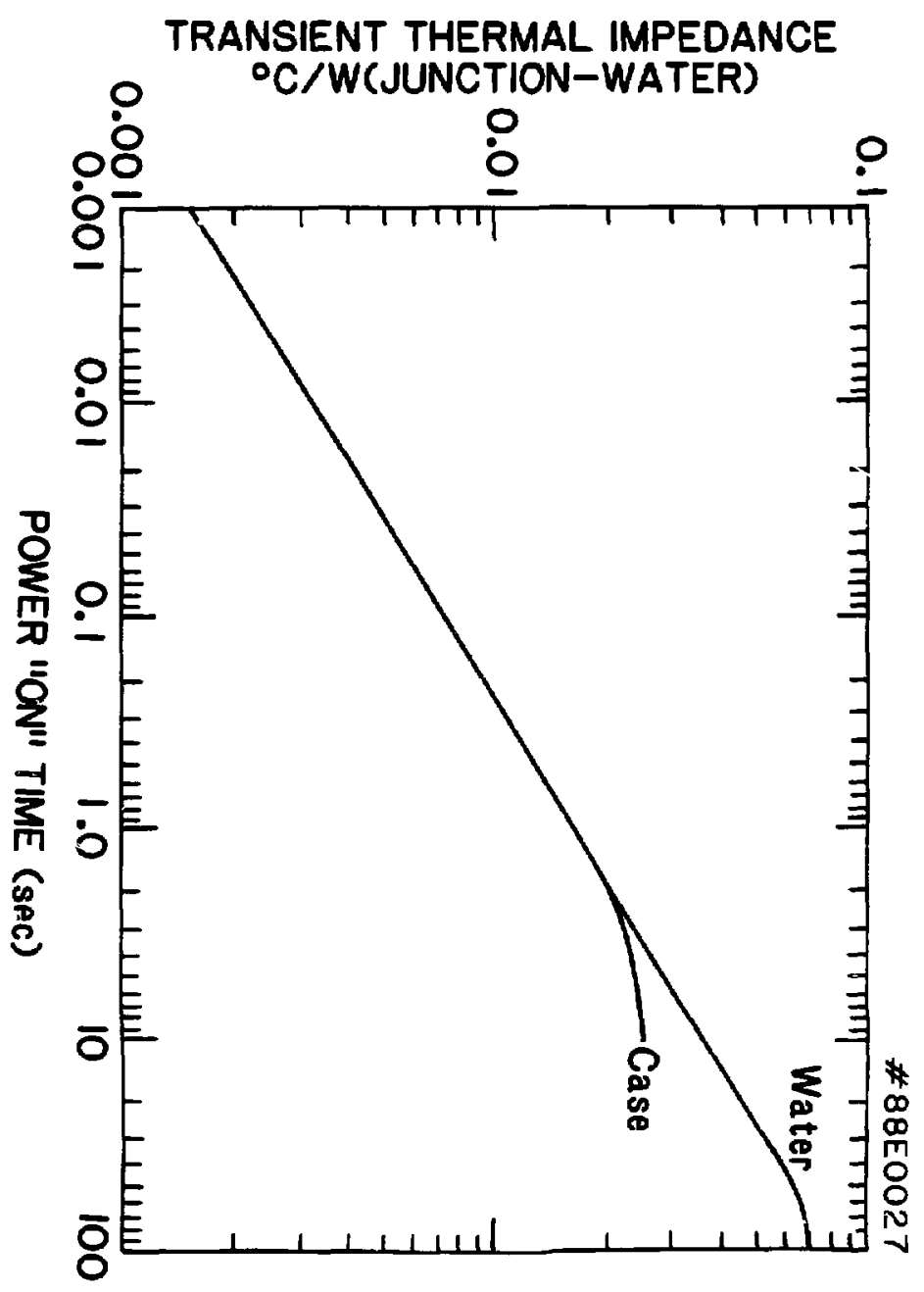




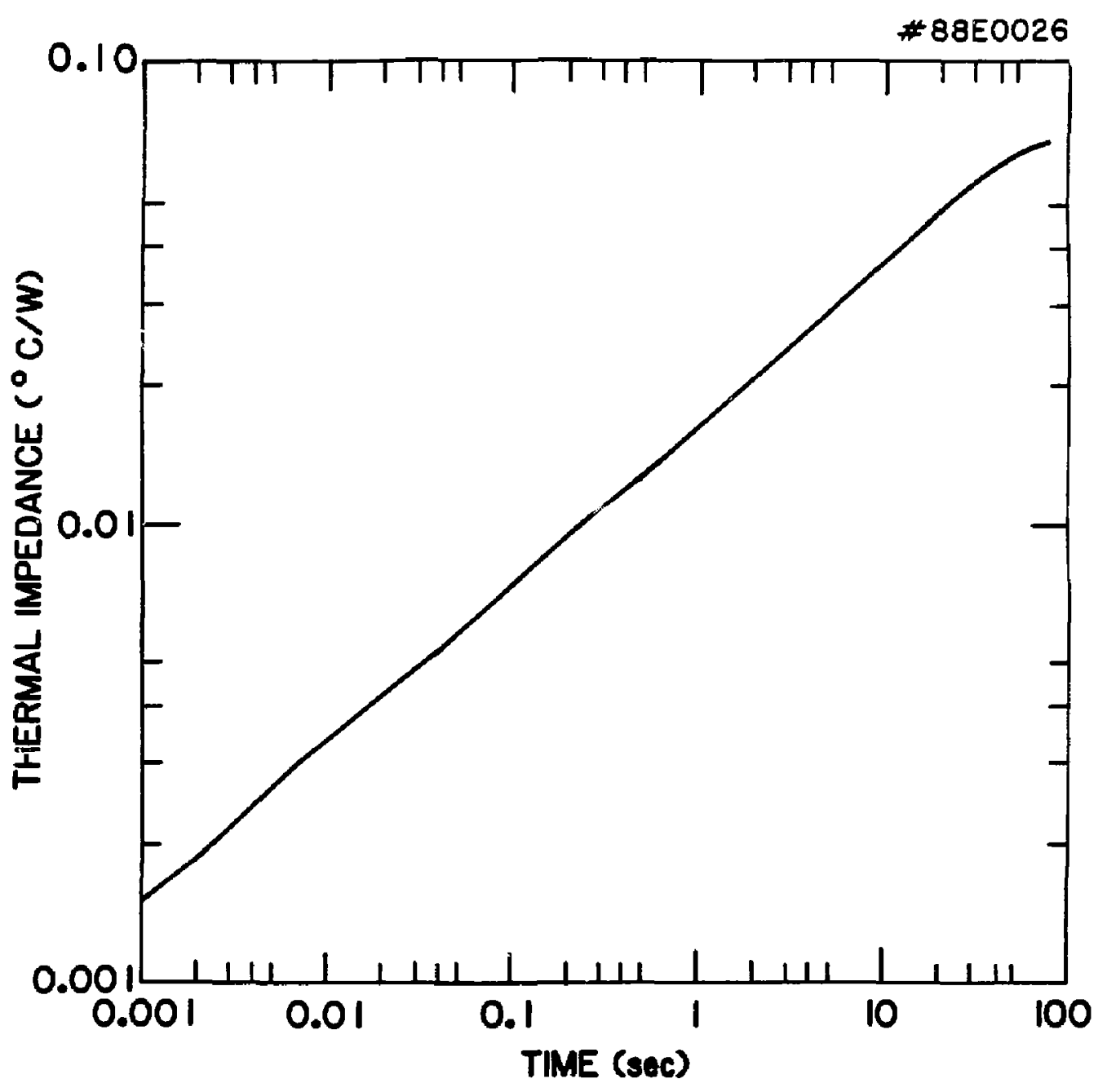

Fir. 6 
THERMAL MODEL OF THYRISTOR

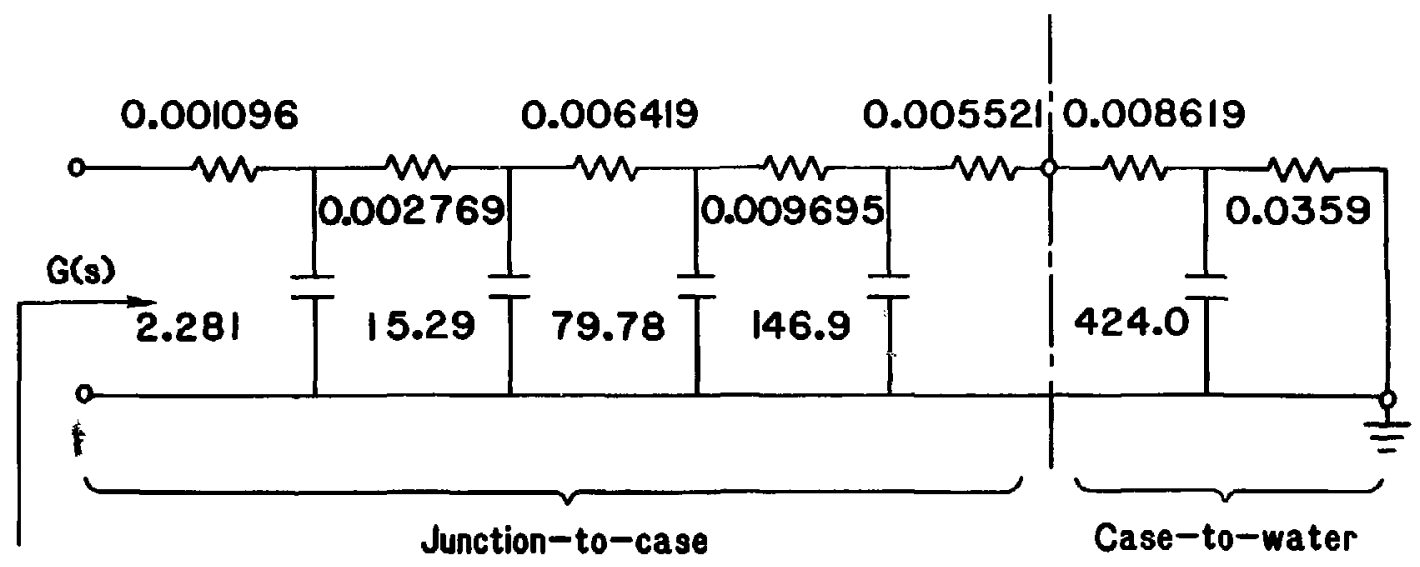

Eig 5 
\#88E0022

\section{ILLUSTRATION OF OONVOLUTION}
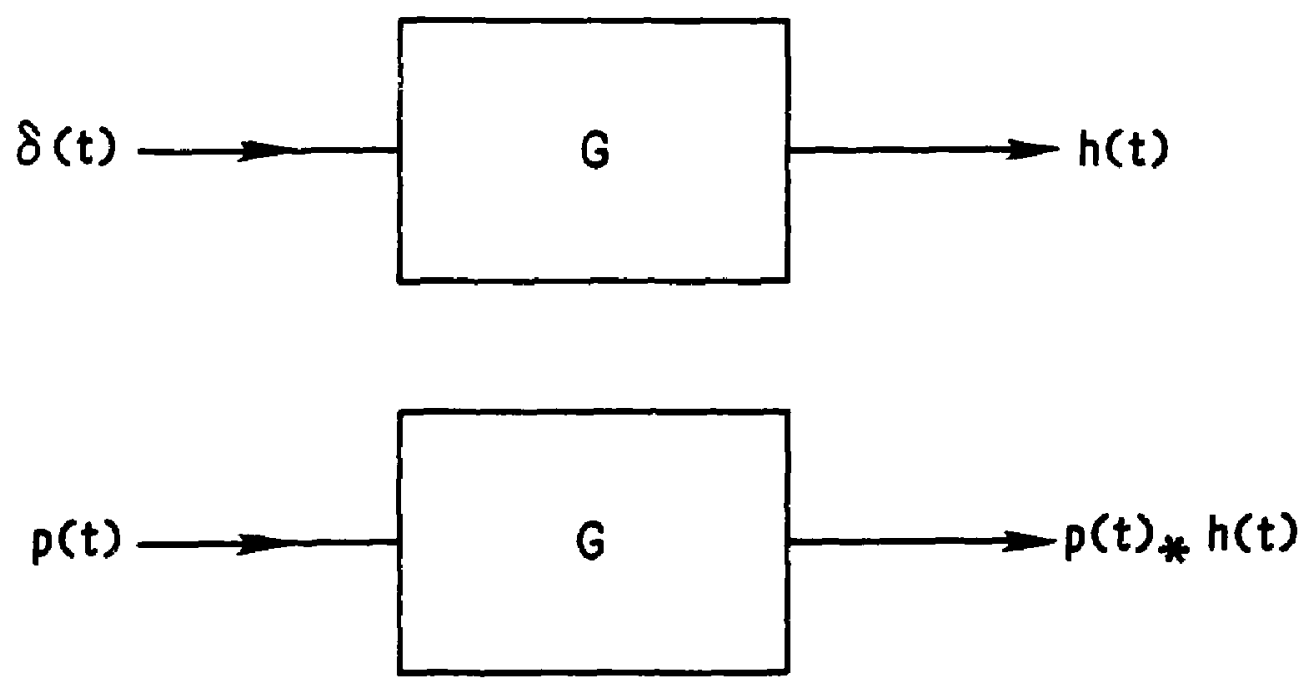

Fig. 7 


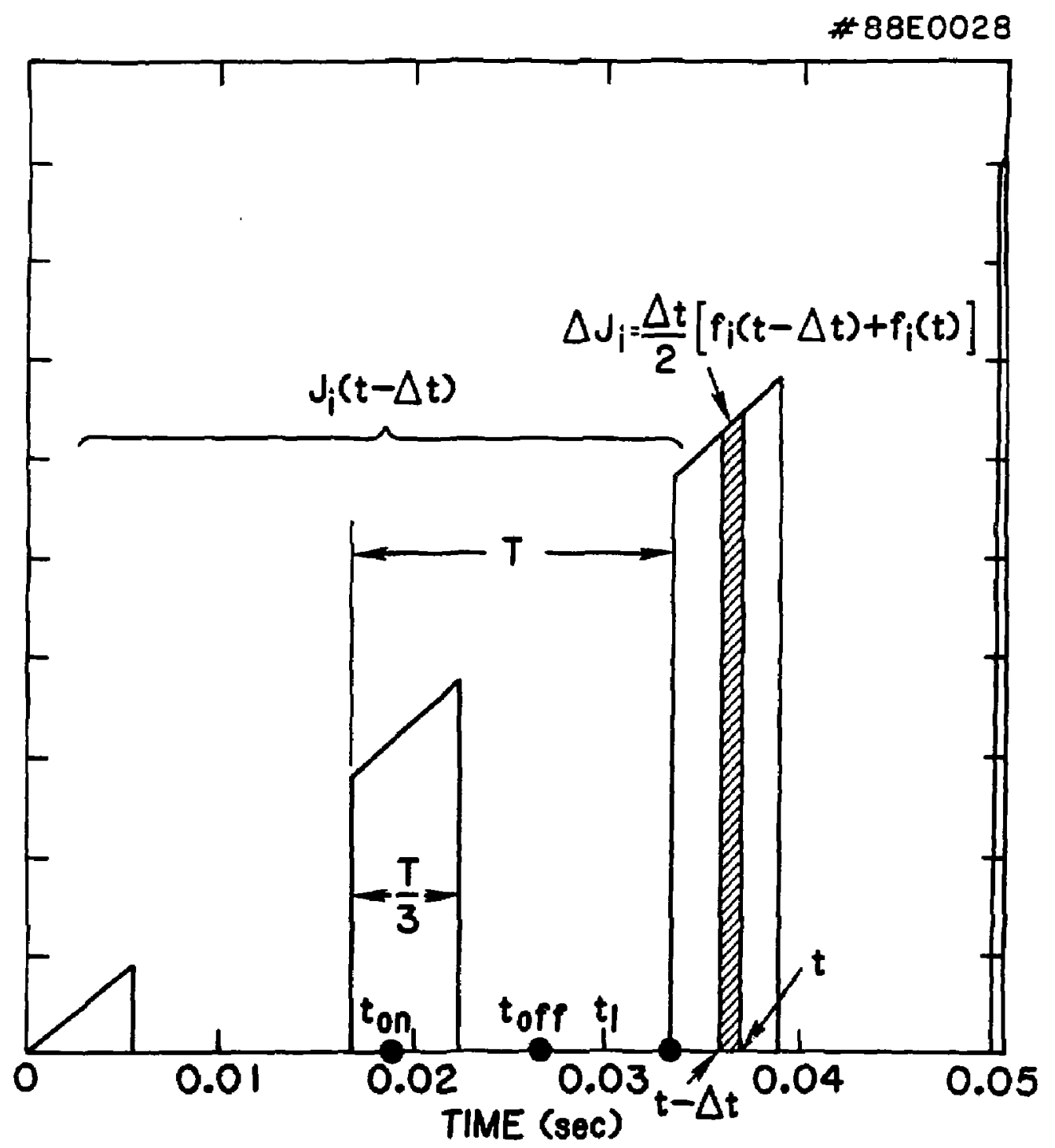

Fig. 8

28 
\# 88E0024
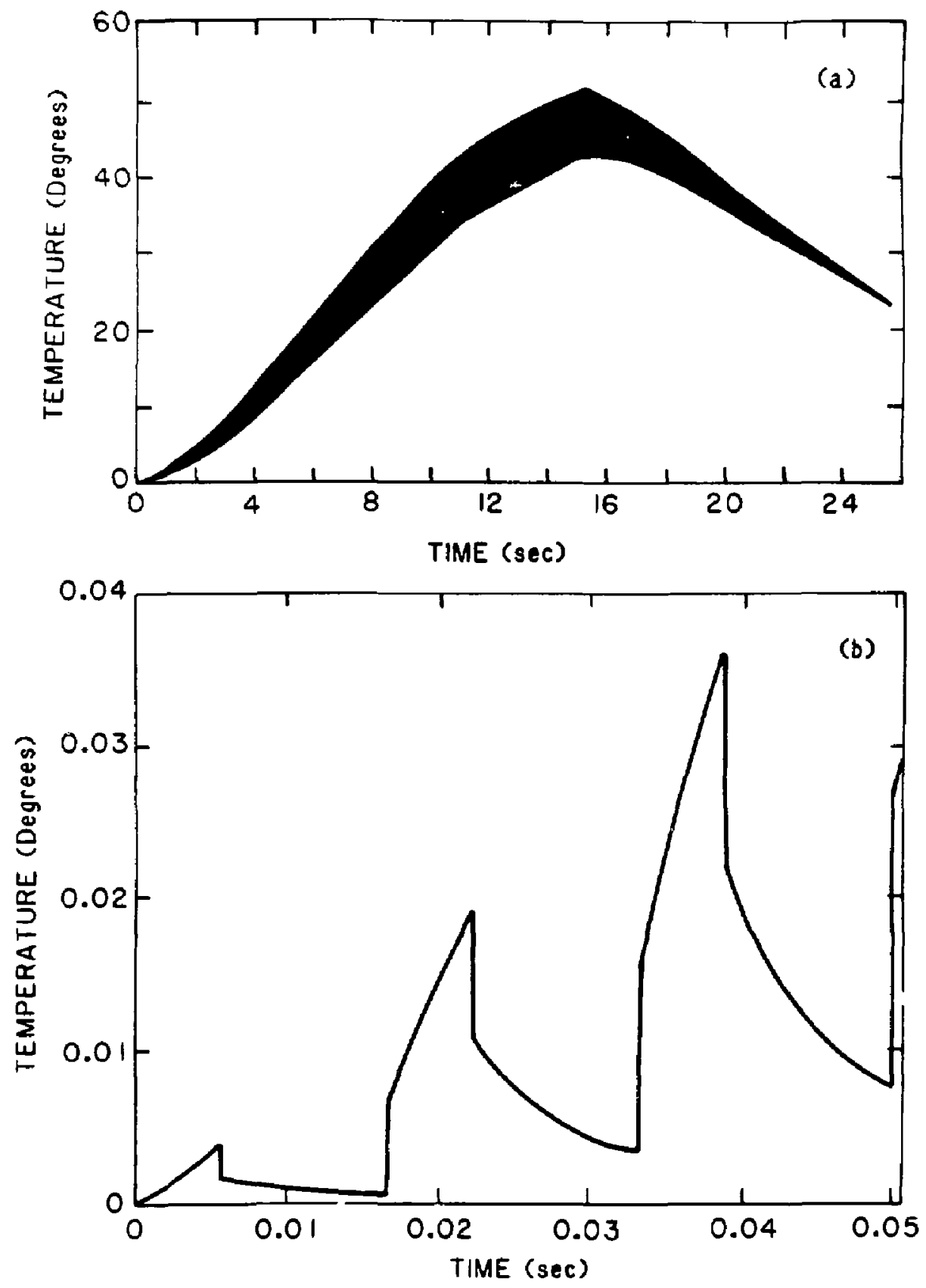

Elg 9 
Dr. Frank J. Paoloni, Univ of Wol longong, AUSTRALIA Prof. M.H. Brennan, Univ Sydney, AUSTRALIA

Plasas Research Lab., Australian Nat. Univ., Australia

Prot. I.R. Jones, Fi inders Univ., AustRaLIA

Prof. F. Cap, Inst Theo Phys, AustRia

Prot. M. Heindler, Institut fur Theoretische Physik, AUSTRIA

M. Goossens, Astronomisch Instituut, BELGIUm

Ecole Royale Militaire, Lab de Phys Plasmas, eELGIUM

Comission-Eurogean, Dg-XII fusion Prog, BELgIum

Prof, R. Boucique, Laboratorium voor Natuurkunde, BELGIUA

Dr. P.H. Sakjnaka, Instituto fisiea, BRzIL

Instituto De Pasquisas Espaciasi-INPE, BazIL

Documents Office, Atomic Energy of Canada Linitad, CNwADA

Dr. M.P. Bechynski, MPB Technologies, Ine., CANADA

Dr. H.M. Skarsgard, University of Saskatchewan, CANADA

Dr. H. Barnard, University of British Columbia, CAMDA

Prof. J. Toichmann, Univ. of Montraal, CANAOA

Prof. S.R. Sreanivasan, University of Calgary, CANADA

Prof. Tudor W. Johnston, INRS-Energie, CNuaA

Dr. C.R. James, Univ. of Alberta, CAMNOA

Or. Peter Lukec, Komenskeho Univ, CzeCHoSlOvakiA

The Librarian, Culha Laboratory, ENGLAND

The Librarian, Rutherford Appleton Laboratory, EMELAND

Mrs. S.A. Hutchinson, JET Library, EMGLANo

C. Mouttet, Lab. de Physique des Milieux Ionises, fRarce

J. Radat, CEH/CAOARACHE - Bat 506, FRunce

Univ. of loannina, Library of Physics Dept. GeeEce

Dr. Tam Mual, Acadeay Bibllographic Ser., Howg Kows

Preprint Library, Hungari an Acadeay of Sciences, huwghry

Dr. B. Dasgupta, Saha Inst of Nuel, Phys., INDIA

Or. P. Kaw, Institute for Pl asma Research, INDIA

Dr. Philip Rosenau, Israel Inst. Tach, ISRAEL

Librarian, Int'I Ctr Theo Phys, ITALY

Prof. G. Rostagni, Univ Di Padova, ITALY

Miss Clelia on Palo, Assoc EuRaton-EhEa, ITALY

Biblioteco, Instituto di fisica del Plasas, ITALY

Dr. H. Yanato, Toshlba Ras 8 Dov, JAPAY

Prof. 1. Kawskani, Atalie Energy Res. Ingtitute, JAPAN

Prof. Kyoji Nishikawa, Univ of Hiroshima, JAPAN

Dirac. Dept, Larg* Tokanak ROS. JAERI, JAPAN

Prof. Satoshi Itoh, Krustiv University, JAPAN

Research Info Canter, Negoye University, JAPAN

Prof. S. Tanaka, Kyoto University, JAPAN

Library, Kyoto Univarsity, JAPAH

Prof. Nobuyuki inowe. University of Tokyo, JAPAN

S. Mor $i$, JAERI, JAPAN

Librarian, Korea Advanced Energy Res. Institute, KOREA

Prof. D.1. Choi, Adv. Inst Sci a Tech, KOPEA

Prof. 8.5. Liloy, University of Halkato, NEW ZEALAND

institute of PIssma Physics, PEOPLE'S REPU⿴LIC OF CHIMA

Librarlan, Institute of Phys., PEOPLE'S REPJELIC Of CHIMA

Library, Tsing Hua University, PEOPLE'S REPUBLIC Of CHIM
2. Ei, Southwest Inst. Physics, PEOPLE'S REPUBLIC of CHINA Prof. J.A.C. Cabral, Inst Suparior Tecnico, PORTUGal Or. Oetavian Petrus, AL I CUzA University, ROManIA Dr. Johan de Villiors, fusion Studies, AEC, SO AFRICA Prof. M.A. Hallbarg, University of Notal, SO AFRICA

C.T.E.M.A.T., Fusion Div. Library, SPAIM

Dr. Lennert Stenflo, University of LMEA, SWEDEN

Library, Royal Inst Toch, SWEDEN

Prof. Hans wilnelmson, Chaimars Univ Tech, SwEDEN

Centre Phys des Plasmas, Ecole Polytech Fed, SWITZERLANo

Bibliothaek, Fom-Inst Voor Piasma-Fysica, THE NETHERLANOS

Dr. D.D. Ryutov, Siberian Acad Sei, USSR

Dr. G.A. Elisen, Kurchetov Institute, USSR

Dr. Y.A. Glukhikh, Inst Electrophysical Apparatus, USSR

Dr. V.T. Tolok, Inst. Phys. Tuch. USSR

Dr. L.M. Kourizhnykh, Institute Gen. Physics, USSR

Nuclear Ros. Establ ishment, Julich Ltd., W. GEPMANY Bibl iothek, Inst. Fur Plasmaforschung, W. GERMANY Or. K. Schindler, Ruhr Univarsitat Bochum, W. GERuAN ASOEX Reading Ro, IPP/Max-Planck-Institut fur

Plasmaphyslk, W. GERMNy

Librarian, Maxplanck institut, W. Gerwany

Prof. R.K. Janev, Inst Phys, yugoslayia 